\title{
Celecoxib suppresses hepatoma stemness and progression by up-regulating PTEN
}

\author{
Tian-Huei Chu ${ }^{1, *}{ }^{,}$Hoi-Hung Chan ${ }^{2,3,4,5, *}$, Hsiao-Mei Kuo ${ }^{6}$, Li-Fen Liu', Tsung-Hui \\ $\mathrm{Hu}^{8}$, Cheuk-Kwan Sun ${ }^{9}$, Mei-Lang Kung ${ }^{10}$, Shih-Wei Lin ${ }^{11}$, E-Ming Wang ${ }^{2,3}$, Yi-Ling \\ $\mathrm{Ma}^{2}$, Kwan-Hung Cheng ${ }^{1}$, Kwok Hung Lai ${ }^{3,4}$, Zhi-Hong Wen ${ }^{13}$, Ping-I Hsu ${ }^{3,4}$ and \\ Ming-Hong Tai ${ }^{1,2,14}$ \\ ${ }^{1}$ Institute of Biomedical Sciences, National Sun Yat-sen University, Kaohsiung, Taiwan \\ 2 Department of Biological Sciences, National Sun Yat-sen University, Kaohsiung, Taiwan \\ ${ }^{3}$ Division of Gastroenterology, Department of Internal Medicine, Kaohsiung Veterans General Hospital, Kaohsiung, Taiwan \\ ${ }^{4}$ School of Medicine, National Yang-Ming University, Taipei, Taiwan \\ ${ }^{5}$ College of Pharmacy \& Health Care, Tajen University, Pingtung County, Taiwan \\ ${ }^{6}$ Mitochondrial Research Unit, Kaohsiung Chang Gung Memorial Hospital and Chang Gung University College of Medicine, \\ Kaohsiung, Taiwan \\ 7 Department of Biological Science and Technology, I-Shou University, Kaohsiung, Taiwan \\ ${ }^{8}$ Division of Hepato-Gastroenterology, Department of Internal Medicine, Chang Gung Memorial Hospital Kaohsiung Medical \\ Center, Chang Gung University College of Medicine, Kaohsiung, Taiwan \\ ${ }^{9}$ Department of Medical Education, E-DA Hospital, I-Shou University, Kaohsiung, Taiwan \\ ${ }^{10}$ Department of Chemistry, National Sun Yat-sen University, Kaohsiung, Taiwan \\ ${ }^{11}$ Institute of Marine Biotechnology, National Sun Yat-sen University, Kaohsiung, Taiwan \\ 12 Department of Medical Education; Digestive Center, E-DA Hospital, Kaohsiung County, Taiwan \\ ${ }^{13}$ Department of Marine Biotechnology and Resources, Asia-Pacific Ocean Research Center, National Sun Yat-Sen University, \\ Kaohsiung, Taiwan \\ ${ }^{14}$ Center for Neuroscience, National Sun Yat-Sen University, Kaohsiung 804, Taiwan \\ * These authors contributed equally to this work \\ Correspondence to: Ming-Hong Tai, email: minghongtai@gmail.com \\ Keywords: hepatocellular carcinoma, hepatic cancer stem cells, celecoxib, prostaglandin E2, phosphatase and tensin homolog. \\ Received: September 4, $2013 \quad$ Accepted: December 28, $2013 \quad$ Published: December 28, 2013
}

This is an open-access article distributed under the terms of the Creative Commons Attribution License, which permits unrestricted use, distribution, and reproduction in any medium, provided the original author and source are credited.

\section{ABSTRACT:}

Celecoxib, a cOX-2 inhibitor and non-steroidal anti-inflammatory drug, can prevent several types of cancer, including hepatocellular carcinoma (HCC). Here we show that celecoxib suppressed the self-renewal and drug-pumping functions in HCC cells. Besides, celecoxib depleted $\mathrm{CD}^{4} 4^{+} / \mathrm{CD} 133^{+}$hepatic cancer stem cells (hCSC). Prostaglandin E2 (PGE2) and CD133 overexpression did not reverse the celecoxibinduced depletion of hCSC. Also, celecoxib inhibited progression of rat Novikoff hepatoma. Moreover, a 60-day celecoxib program increased the survival rate of rats with hepatoma. Histological analysis revealed that celecoxib therapy reduced the abundance of $\mathrm{CD}_{44}{ }^{+} / \mathrm{CD}_{133}{ }^{+}$hCSCs in hepatoma tissues. Besides, the hCSCs depletion was associated with elevated apoptosis and blunted proliferation and angiogenesis in hepatoma. Celecoxib therapy activated peroxisome proliferator-activated receptor Y (PPARY) and up-regulated PTEN, thereby inhibiting Akt and disrupting hCSC expansion. PTEN gene delivery by adenovirus reduced CD44/CD133 expression in vitro and hepatoma formation in vivo. This study suggests that celecoxib suppresses cancer stemness and progression of HCC via activation of PPARY/PTEN signaling. 


\section{INTRODUCTION}

Hepatocellular carcinoma (HCC) accounts for $70-85 \%$ of liver cancers and is one of the most common malignancies worldwide [1]. Current HCC therapies include surgery, liver transplantation, chemotherapy, transarterial chemoembolization (TAE), and radiofrequency ablation [2]. However, the overall prognosis for HCC remains poor. Sorafenib, an inhibitor of multiple kinases, including vascular endothelial growth factor receptor (VEGFR), platelet-derived growth factor receptor (PDGFR), and Raf kinases, is currently the only target therapy for HCC $[3,4]$. However, the high cost and limited pro-survival effect of sorafenib warrant further development of therapeutic alternatives for HCC.

Cyclooxygenase-2 (COX-2) is an inducible enzyme frequently found in inflammatory tissues and is involved in carcinogenesis pathways in many organs. It has been reported that COX-2 expression is correlated with angiogenesis, invasion, relapse, chemoresistance, and tumorigenesis in HCC [5]. Besides, a significant correlation between COX-2 expression and active inflammation in the adjacent non-cancerous liver is associated with shorter disease-free survival in HCC patients [6]. COX-2 promotes hepatoma cells growth and inhibits cell apoptosis through Akt activation $[7,8]$. Prostaglandin E2 $\left(\mathrm{PGE}_{2}\right)$, the major product of COX-2, stimulates the proliferation, migration, and invasion in hepatoma cells by activating $\beta$-catenin and Akt signaling [9].

Cancer stem cells (CSCs), the rare and most malignant subpopulations in tumors, are maintained by indefinitely self-renew abilities and resistant to drug therapy $[10,11]$. CD133 is a universal marker of stem cells and CSCs and $\mathrm{CD} 133^{+}$hepatic cancer stem cells (hCSCs) tumor cells have been identified to exhibit properties of CSCs in human HCC and mouse liver cancer [12-14]. Indeed, $\mathrm{CD}_{133^{+}}$hCSCs cells have higher expression and increased activity of aldehyde dehydrogenase (ALDH) to promote their tumorigenicity [13]. Moreover, a recent study has indicated that high expression levels of hCSCs biomarkers, including CD133 and CD44, are correlated with tumor angiogenesis and poor prognosis of HCC patients [15]. Though not fully elucidated, several signaling pathways, including Akt and $\mathrm{Wnt} / \beta$-catenin, have been implicated in the CSCs maintenance [11]. Besides, inhibition of Akt signaling leads to decreased CD133 and CD44 expression in HCC cells $[16,17]$.

Celecoxib, a selective COX-2 inhibitor and nonsteroidal anti-inflammatory drug (NSAID), is widely used for pain and inflammation. Celecoxib attenuates Akt phosphorylation and induces growth inhibition and apoptosis in HCC cells, which can be partially reversed by ectopic COX-2 expression and $\mathrm{PGE}_{2}$ [8]. The chemopreventive effect of celecoxib has been demonstrated in animal models of diethylnitrosamineinduced HCC [18] and Huh7 xenograft hepatoma [19]. Both COX-2-dependent and COX-2-independent pathways contribute to celecoxib-mediated HCC chemoprevention [20]. However, the therapeutic efficacy of celecoxib for HCC has not been tested in immunecompetent animals with orthotopic hepatoma. Thus, this study investigated the therapeutic potential and mechanism of celecoxib in rat Novikoff hepatoma induced by US-guided implantation [21].

\section{RESULTS}

\section{PGE2 from non-tumor tissues induces differential distribution of liver cancer stem cells in Novikoff hepatoma}

Poorly differentiated HCCs expressed less COX2 than surrounding hepatocytes of non-tumor region [22], and COX-2 expression in non-tumor tissue play a positive role in relapse of HCC after surgery [6]. We first examined COX-2 expression and the spatial distribution of $\mathrm{CD}_{4} 4^{+} / \mathrm{CD} 133^{+}$hCSCs in Novikoff hepatoma using immunohistochemical and immunofluorescent analyses, respectively. COX-2 immunostaining was primarily localized in non-tumor hepatic tissues, but was only minimally detected in Novikoff hepatoma. Moreover, $\mathrm{CD}_{4} 4^{+} / \mathrm{CD} 133^{+} \mathrm{hCSC}$ abundance was increased in regions near COX-2-expressing non-tumor tissues compared with regions that were farther away (Fig. 1A). Based on the lack of COX-2 expression in hepatoma, it was hypothesized that $\mathrm{PGE}_{2}$ originated from the COX-2expressing liver and promoted the generation of cancer stem cells in Novikoff hepatoma. To test this hypothesis, comparative analysis of COX-2 expression between N1S1 rat hepatoma cells and Clone-9 rat liver cells showed that COX-2 mRNA and protein levels were significantly higher in Clone-9 cells than in N1-S1 cells (Fig. 1B). Additionally, COX-2-expressing Clone-9 cells secreted significantly higher amounts of $\mathrm{PGE}_{2}$, whose production was significantly inhibited by treatment with celecoxib (Fig. 1C). $\mathrm{PGE}_{2}$ secretion was not detectable in N1S1. We then investigated whether conditioned medium (CM) from Clone-9 cells, which contained a high $\mathrm{PGE}_{2}$ content, influenced the generation of hCSCs in N1-S1 cells. Flow cytometry analysis showed that co-culture with CM from Clone-9 cells significantly enhanced the abundance of $\mathrm{CD}_{4} 4^{+} / \mathrm{CD} 133^{+}$hCSCs in N1-S1 cells (Fig. 1D). This stimulatory effect was diminished in CM from celecoxib-treated Clone-9 cells, indicating that $\mathrm{PGE}_{2}$ has a stimulatory function in hCSC genesis. Moreover, immunoblot analysis showed that incubation with CM from Clone-9 cells elevated expression of CD44 
and CD133 in N1-S1 cells (Fig. 1E), whereas CM from celecoxib-treated clone-9 cells upregulated CD44 and CD133 to a lesser extent. These results suggest that $\mathrm{PGE}_{2}$ from hepatic tissues induces differential hCSC distribution in Novikoff hepatoma.

\section{Celecoxib suppresses the function and abundance of cancer stem-like cells in HCC cells}

We first evaluated the anti-neoplastic efficacy of celecoxib in vitro by cell proliferation assay and colony formation assay, respectively. Despite moderate inhibition on cell proliferation (Supplementary Fig. 1A and B),

A

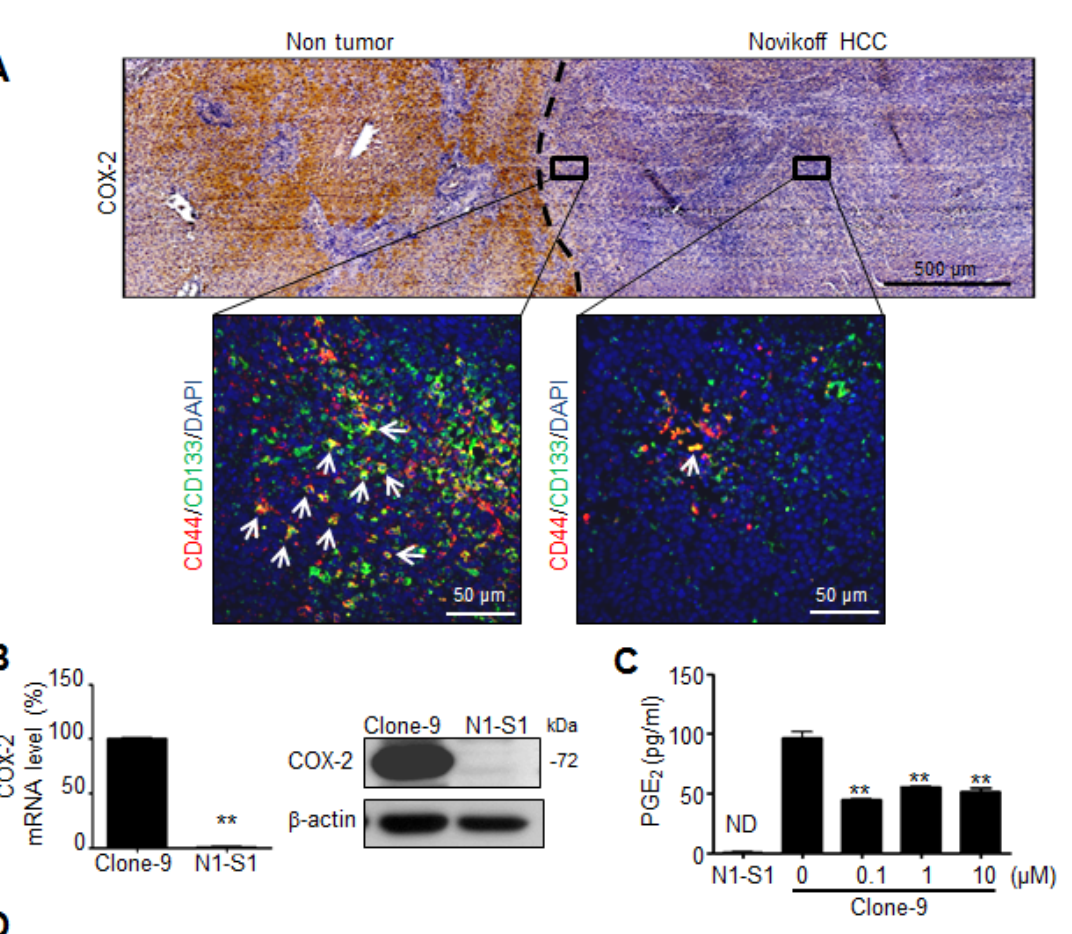

Novikoff HCC

D
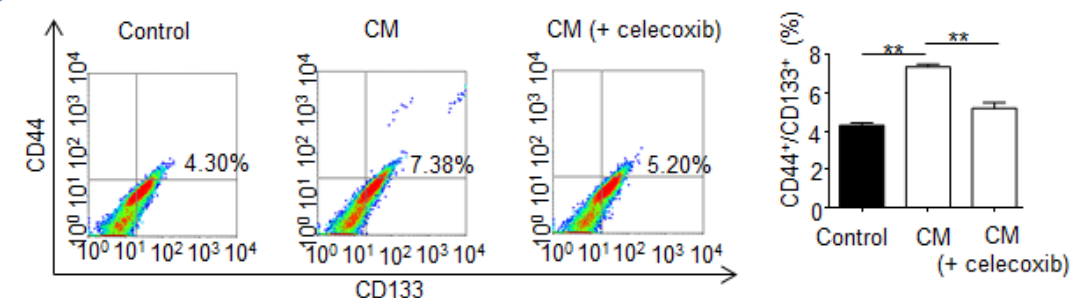

$\mathbf{E}$
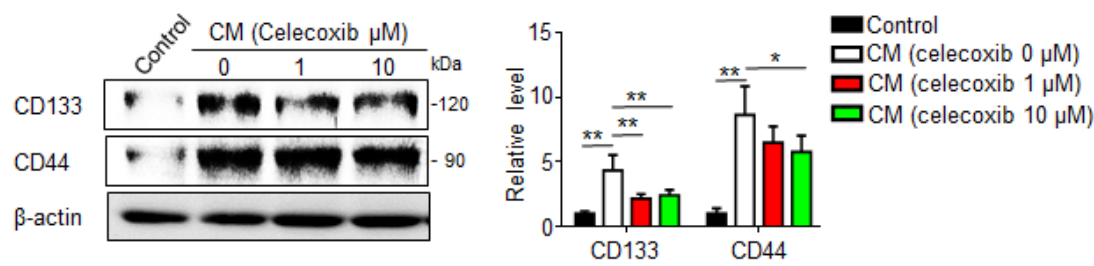

Fig 1: PGE2 from non-tumor tissues enhanced the cancer stemness of Novikoff HCC. (A) Histological analysis of COX-2 expression and $\mathrm{CD} 44^{+} / \mathrm{CD} 133^{+}$hCSCs distribution in Novikoff hepatoma. (Top panel) Immunohistochemical studies showed elevated COX-2 expression in non-tumor hepatic tissues compared with that in Novikoff hepatoma. (Bottom insets) Immunofluorescence analysis revealed higher abundance of $\mathrm{CD} 44^{+} / \mathrm{CD} 133^{+} \mathrm{hCSCs}$ in regions adjacent to non-tumor tissues (left inset) than the farther away ones (right inset). White arrow indicated CD $44^{+} / \mathrm{CD} 133^{+}$hCSCs. (B) Quantitative RT-PCR and immunoblot analysis of COX-2 expression in Clone-9 and N1-S1 cells. (C) EIA analysis of $\mathrm{PGE}_{2}$ secretion in N1-S1 cells and Clone-9 cells after treatment with varying doses of celecoxib for $48 \mathrm{~h}$. ND, not detectable. (D) Conditioned media (CM) of Clone- 9 cells were exposed to $10 \mu \mathrm{M}$ celecoxib for $48 \mathrm{~h}$ in $0.1 \%$ serum F-12K medium, and then N1-S1 cells were incubated in Clone-9 conditioned medium (CM) for an additional 48 h. Next, $0.1 \%$ serum F-12K medium was incubated for $48 \mathrm{~h}$ to prepare control medium for N1-S1 co-culture. After N1-S1 cells were cultured in celecoxib-treated Clone-9 culture medium (CM) or control medium, N1-S1 cells were collected to evaluate the ratio of CD44 $/ \mathrm{CD} 133^{+}$cells using flow cytometry, and statistic results are shown. (E) Immunoblot analysis for CD44 and CD133 in N1-S1 cells treated with control medium or $\mathrm{CM}$, and statistic results are shown. Data are mean $\pm \mathrm{SD}\left({ }^{*} p<0.05, * * p<0.01\right)$. 
celecoxib inhibited the oncogenic behaviors, including invasiveness (data not shown) and anchorage-independent growth (Supplementary Fig. 1C and D), in human Hep3B and Huh7 cells respectively with a half-maximal inhibitory concentrations $\left(\mathrm{IC}_{50}\right)$ of 31.32 and $29.33 \mu \mathrm{M}$. We subsequently investigated the influence of celecoxib on hCSCs functions in HCC cells in the absence or presence of $\mathrm{PGE}_{2}$. By using sphere formation assay to evaluate the self-renewal capability of hCSCs [23], it was found that celecoxib potently inhibited the basal or $\mathrm{PGE}_{2}$-stimulated sphere formation in human (Huh-7) and rat (N1-S1) HCC cells (Fig. 2A). To study the drug efflux functions of hCSCs using side population (SP) analysis [24], it was observed celecoxib also attenuated the endogenous and $\mathrm{PGE}_{2}$-induced drug-pumping capability in N1-S1 cells (Fig. 2B). Together, these results indicated that celecoxib perturbs the hCSCs functions in HCC cells.

We then evaluated whether celecoxib affected the abundance of $\mathrm{CD} 44^{+} / \mathrm{CD} 133^{+} \mathrm{hCSCs}$ in hepatoma cells. $\mathrm{PGE}_{2}$ is a potent stem cells regulator, and it can promote stem cells function [25]. We also found that exogenous $\mathrm{PGE}_{2}$ induced up-regulation of CD44 and CD133 hCSCs
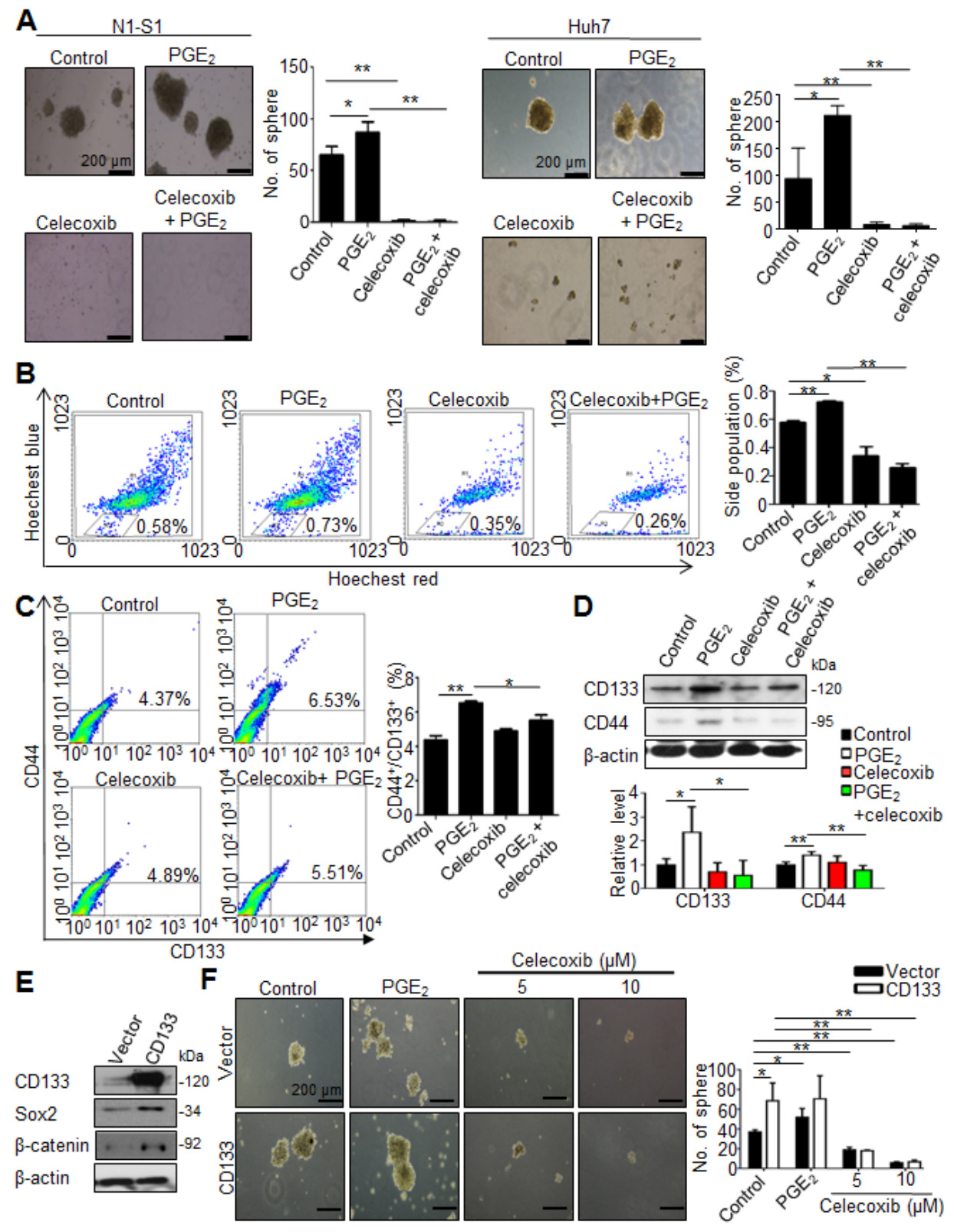

Fig 2: Celecoxib inhibited the function and abundance of hCSC in HCC cells. (A) Effect of celecoxib on spheres formation in N1-S1 and Huh7 cells with or without $\mathrm{PGE}_{2}$ pretreatment. (B) Effect of celecoxib on side population cells in N1-S1 cells with or without $\mathrm{PGE}_{2}$. (C) Flow cytometry analysis of the effect of celecoxib on CD133 $/ \mathrm{CD}_{4} 4^{+}$hCSCs in N1-S1 cells with or without PGE $2_{2}$ (D)

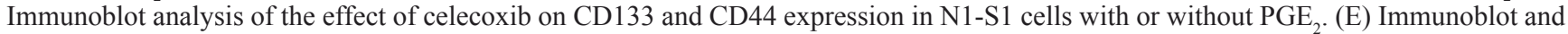
(F) sphere formaiton analysis in retro-CD133 or retro-vector infectd-N1-S1 cells. Data were mean $\pm \mathrm{SD}\left({ }^{*} p<0.05, * * p<0.01\right)$. 
marker in human Hep3B and Huh7 cells (Supplementary Fig. 2). Flow cytometry analysis showed that celecoxib significantly attenuated the $\mathrm{PGE}_{2}$-induced $\mathrm{CD}_{4} 4^{+} / \mathrm{CD}_{13} 3^{+}$ hCSCs in N1-S1 cells (Fig. 2C). Besides, celecoxib treatment significantly decreased the CD133 and CD44 protein levels in $\mathrm{PGE}_{2}$-stimulated N1-S1 cells (Fig .2D). To test whether CD133 overexpression could revert the celecoxib-induced hCSCs depletion, we generated CD133-overexpressing N1-S1 cells using retrovirus gene delivery (Fig. 2E). These CD133-overexpressing N1$\mathrm{S} 1$ cells exhibited elevated expression of CSC markers, including Sox 2 and $\beta$-catenin, and enhanced self-renewal ability. Nevertheless, celecoxib supply still significantly abrogated the spheres formation of CD133-expressing N1-
S1 cells at low concentration ( $5 \mu \mathrm{M}$; Fig. 2F). Moreover, combination of CD133 overexpression with excessive $\mathrm{PGE}_{2}$ failed to rescue the celecoxib-induced suppression of sphere formation in N1-S1 cells. Together, these results indicate that celecoxib is an effective blocker of cancer stem-like cells in HCC cells.

\section{Celecoxib therapy perturbs the tumor progression and prolongs the survival in rats bearing Novikoff hepatoma}

Before testing the therapeutic efficacy, we evaluated the chemopreventive effect of celecoxib for Novikoff
A

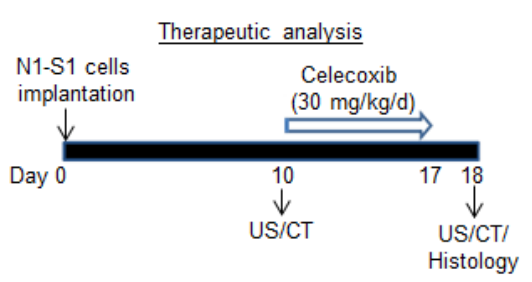

C

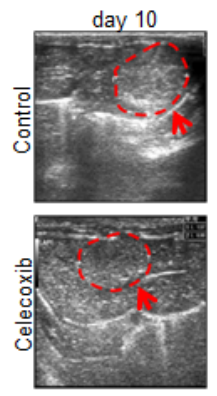

E
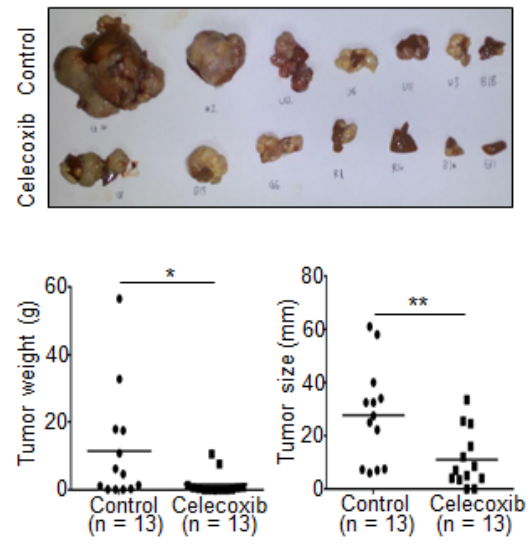

B

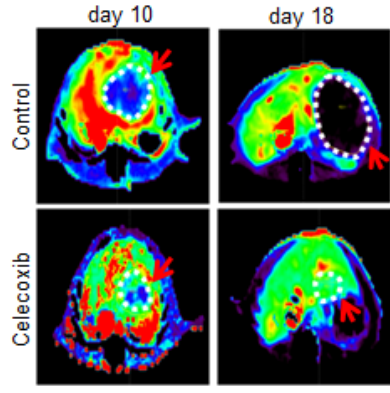

D

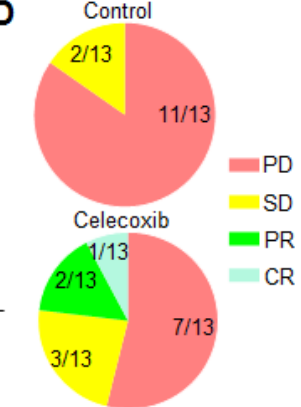

$\mathbf{F}$

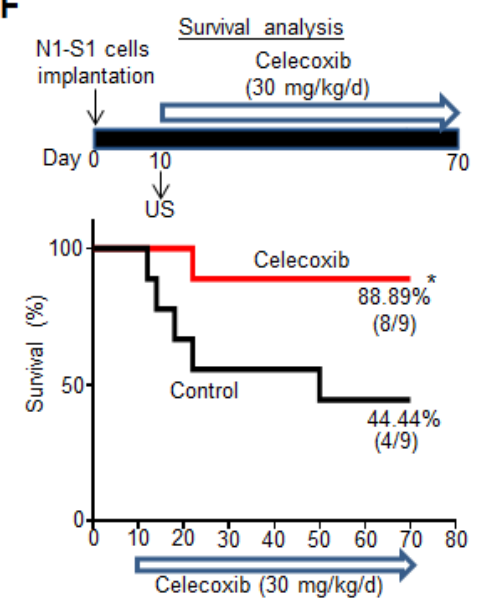

Fig 3: Therapeutic and survival effect of celecoxib in rats bearing established Novikoff hepatoma. (A) Experimental scheme. (B) CT images analysis of rat Novikoff hepatoma before and after celecoxib therapy (arrows indicated the tumors; dotted line depicted the tumor areas). (C) US monitoring of rat Novikoff hepatoma before and after celecoxib therapy (left panel; arrows indicates the hepatoma; dotted line depicted the tumor areas). Statistical analysis of US-measured tumor sizes (right panel). (D) RECIST analysis for the response of celecoxib therapy. (PD, progressive disease; SD, stable disease; PR, partial response; CR, complete response). (E) Photographs of hepatic tumors, microbalance-measured tumor weight and caliper-measured tumor size after animal sacrificing. (F) KaplanMeier survival analysis. ( ${ }^{*} p<0.05,{ }^{*} p<0.01$; NS, no significance). 
hepatoma in rats and found that a 17-day prophylactic celecoxib program significantly reduced the size and weight of Novikoff hepatoma compared with drinking water-treated control (Supplementary Fig. 3A-C). Subsequently, we investigated the therapeutic efficacy of a 7-day celecoxib regimen for established Novikoff hepatoma in rats by serial non-invasive CT and US analysis (Fig. 3A-C). Both CT and US imaging analysis revealed that celecoxib therapy perturbed hepatoma progression. Quantification analysis of US-measured hepatoma diameters showed that mean tumor size in celecoxib-treated group was not significantly increased (from $11.07 \pm 4.30 \mathrm{~mm}$ on day 10 to $14.98 \pm 10.16 \mathrm{~mm}$ on day $18 ; \mathrm{n}=13$ ) whereas mean tumor size in control group was significantly increased within the same period (from $11.31 \pm 8.03$ to $26.5516 .02 \mathrm{~mm} ; p<0.01, \mathrm{n}=$ 13). Moreover, the size of celecoxib-treated hepatoma was significantly smaller than that in control group $(p<0.05$;
Fig. 3C).

According to Response Evaluation Criteria in Solid Tumours (RECIST) ver.1.1 [26], patients with an increase of $20 \%$ or more in lesion size or those with new lesions were regarded as having progressive disease (PD). Patients with a change of lesion size ranging from an increase of $<20 \%$ to a decrease of $<30 \%$ and with no new lesion were stratified as having stable disease (SD). Patients with a $30 \%$ or greater decrease in the target lesion were regarded as achieving partial response (PR). Patients with disappearance of the lesion were stratified as achieving complete response (CR). RECIST analysis showed that $84.62 \%(11 / 13)$ animals showed PD, and 15.38\% $(2 / 13)$ animals showed SD in control group (Fig. 3D). In celecoxib-treated group, 53.85\% (7/13) animals showed PD, 23.08\% (3/13) animals showed SD, 15.38\% (2/13) animals showed PR, and 7.69\% (1/13) animals showed CR. Quantification studies of dissected hepatoma tissues
A

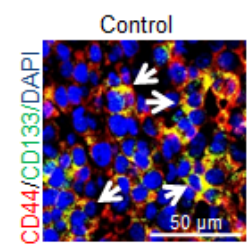

B
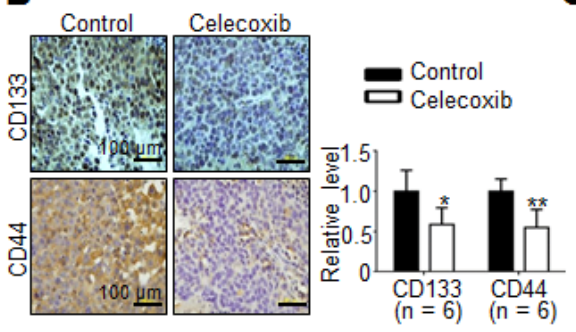

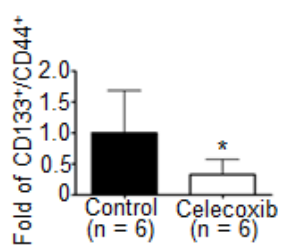

C
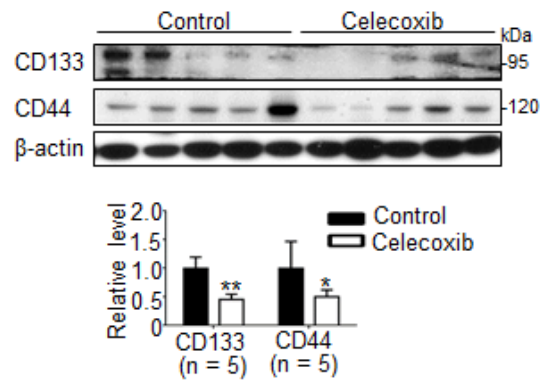

D

E
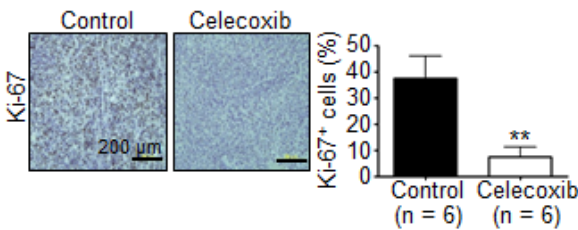

Control
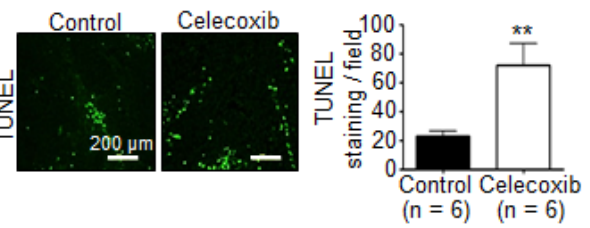

$\mathbf{F}$
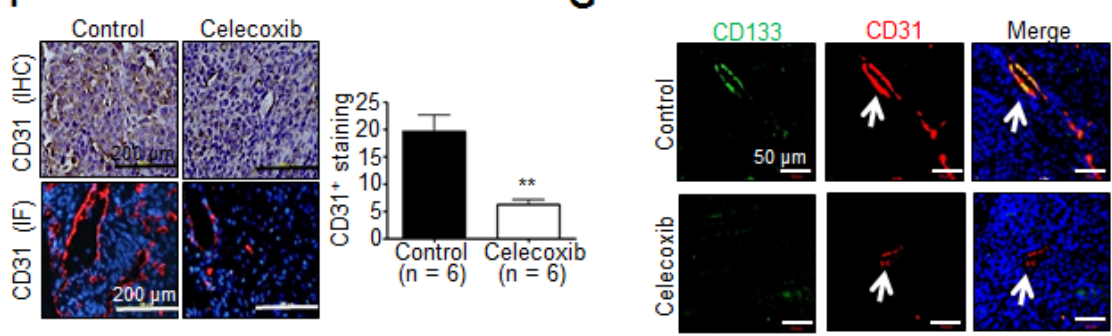

Fig 4: Effect of celecoxib therapy on cancer stemness, proliferation, apoptosis and angiogenesis in Novikoff hepatoma. (A) Immunofluorescence staining (white arrow indicates $\mathrm{CD} 44^{+} / \mathrm{CD} 133^{+} \mathrm{hCSCs}$ in tumor tissues), (B) Immunohistochemestry staining (left panel) and (C) immunoblots (right panel) for CD133 and CD44 from tumor tissues after celecoxib therapy for 7 days. Immunohistological studies of (D) Ki-67, (E) TUNEL and (F) CD31 in control or celecoxib-treated liver tumor. (G) Immunofluorescence analysis for CD133 ${ }^{+} /$ $\mathrm{CD} 31^{+}$endothelium cells in hepatic tumors (white arrow indicates blood vessels in the tumor tissues). $\left({ }^{*} p<0.05, * * p<0.01\right.$ ). 
also confirmed that the weight and size of hepatoma were significantly reduced in rats receiving celecoxib therapy ( $p$ $<0.05$ and $p<0.01$; Fig. 3E).

By using Kaplan-Meier analysis, the survival study indicated a 60-day celecoxib therapy significantly increased the survival rate in rats bearing established hepatoma ( $88.99 \%$ in celecoxib group versus $44.44 \%$ in control; $p<0.05$; Fig. $3 \mathrm{~F}$ ). These findings supported the therapeutic potential of celecoxib in rats with pre-existing hepatoma.

\section{Celecoxib therapy disrupted the hCSCs markers expression and genesis in Novikoff hepatoma}

To investigate whether the anti-tumor effect was associated with the depleted cancer stem cells in celecoxib-treated hepatoma, immunofluorescence analysis reveale that the significantly decreased prevalence of $\mathrm{CD} 133^{+} / \mathrm{CD}_{4} 4^{+}$hCSCs in celecoxib-treated hepatoma than control group (Fig. 4A). Immunohistochemical analysis showed that the immunostaining of CD133 and CD44 was significantly reduced in celecoxib-treated hepatoma compared with that in control (Fig. 4B). This was consistent with the results of immunoblot analysis, which showed a significantly decreased CD133 and CD44 protein levels in celecoxib-treated hepatoma tissues (Fig. 4C). Interestingly, prophylactic celecoxib regimen also suppressed the expression of CD133 and CD44 in tumor tissues (Supplementary Fig. 3D and E). Therefore, celecoxib therapy attenuated the expression of hCSC markers, thereby depleting the hCSC genesis in Novikoff hepatoma.

\section{Celecoxib therapy elicits growth inhibition, apoptosis and angiogenesis blockade in Novikoff hepatoma}

Histological analysis was performed to delineate the anti-neoplastic mechanism of celecoxib therapy other

A
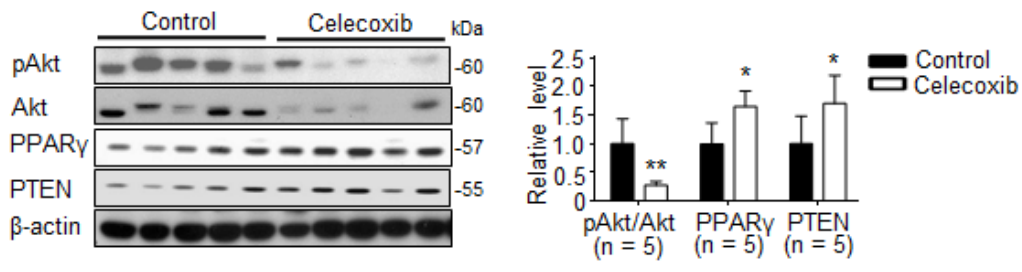

B

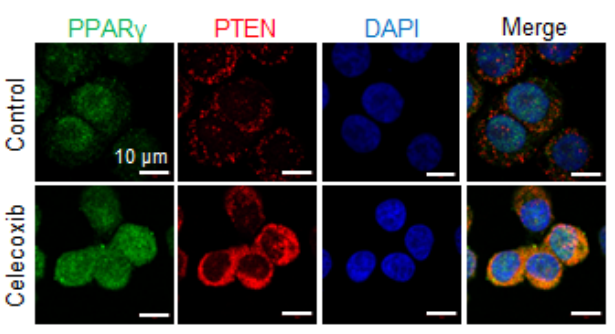

C

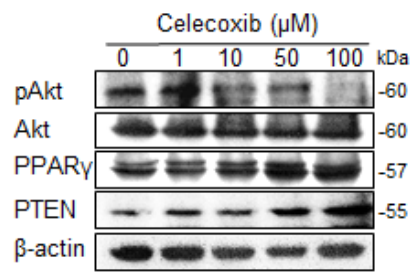

D

\section{E}
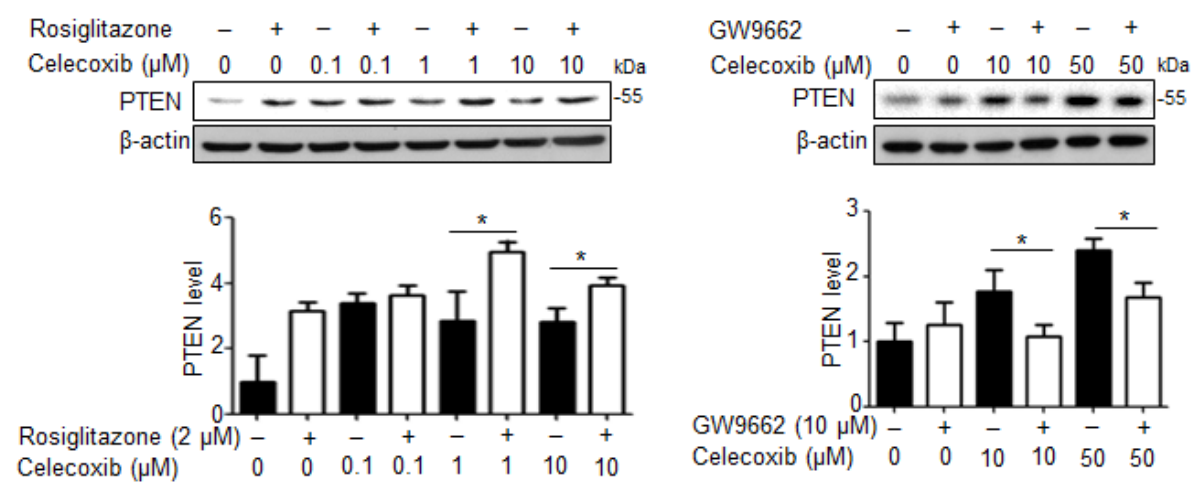

Fig 5: PPAR $\gamma /$ PTEN signaling contributes to celecoxib-induced Akt inhibition. (A) Immunoblots from 7-day celecoxibtreated tumor tissues. (B) Immunofluorescence analysis in N1-S1 cells treated with $10 \mu \mathrm{M}$ celecoxib for $48 \mathrm{~h}$. (C) Immunoblots from N1$\mathrm{S} 1$ cells treated with different dose celecoxib for $48 \mathrm{~h}$. (D) Immunoblots from N1-S1 cells treated with celecoxib for $48 \mathrm{~h}$ in the presence or absence of $2 \mu \mathrm{M}$ rosiglitazone. (E) Immunoblots from N1-S1 cells treated with celecoxib for $48 \mathrm{~h}$ in the presence or absence of $10 \mu \mathrm{M}$ GW9662 $(* p<0.05, * * p<0.01)$. 
than perturbing cancer stemness. By immunostaining of Ki-67, an index of cell proliferation, it was observed that celecoxib therapy significantly decreased the Ki-67positive proliferating cells in hepatoma tissues (Fig. 4D). This was accompanied with an increment in TUNELpositive apoptotic cells (Fig. 4E). Since angiogenesis is critical to the viability of cancer cells, we evaluated the influence of celecoxib on neovascularization in hepatoma tissues. It was noted that the CD31-positive, neovascularized vessels were significantly reduced in celecoxi-treated Novikoff hepatoma (Fig. 4F). A recent study has indicated that $\mathrm{CD} 133^{+} \mathrm{CSC}$ may give rise to tumor endothelium, thereby contributing to tumor vasculature and angiogenesis [27]. Interestingly, immunofluorescence staining unveiled that the $\mathrm{CD}_{133^{+}} /$ $\mathrm{CD} 31^{+}$vessels were significantly diminished in celecoxibtreated hepatoma (Fig. 4G).

\section{Celecoxib induces PPAR $\gamma /$ PTEN activation to disrupt Akt signaling and cancer stemness in hepatoma cells.}

Because Akt signaling is activated in $\mathrm{CD} 133^{+}$ human HCC cells [16], we studied whether Akt pathway
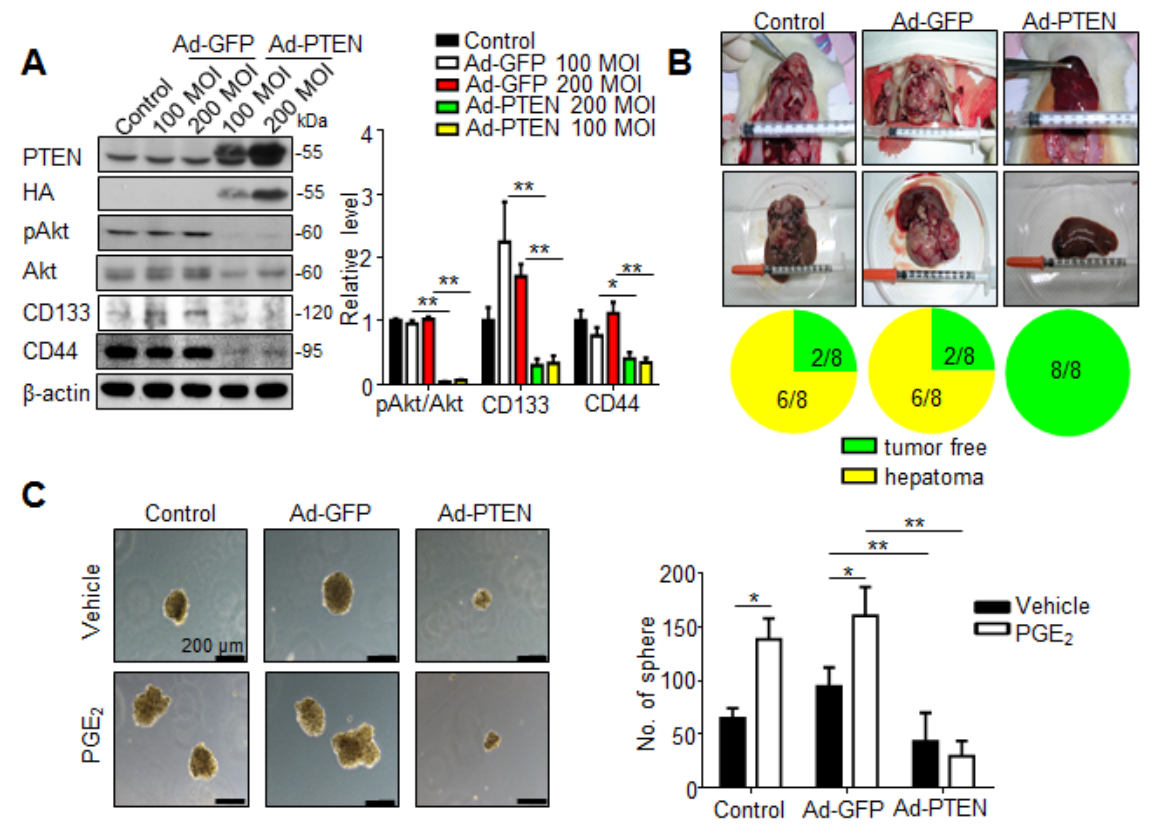

D

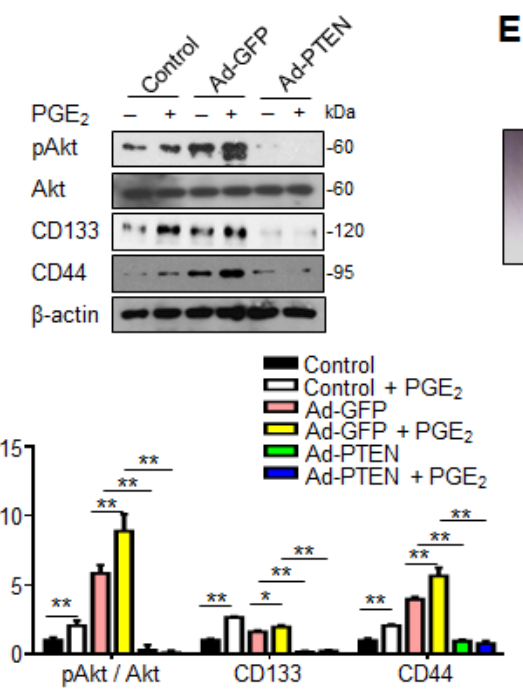

E
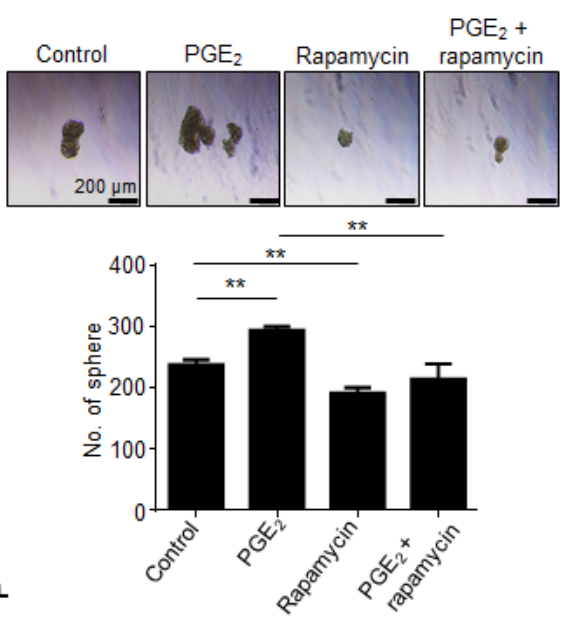

Fig 6: PTEN overexpression suppresses cancer stemness and tumor initiating. (A) Immunoblot analysis in N1-S1 cells infected with Ad-GFP or Ad-PTEN for 48 h. (B) Effect of Ad-GFP (200 MOI) or Ad-PTEN (200 MOI) on tumor induction rate in orthotopic Novikoff hepatoma model. (C) Effect of gene delivery on spheres formation in Ad-GFP-infected (200 MOI) or Ad-PTEN-infected (200 MOI) Huh7 cells with or without $\mathrm{PGE}_{2}(1 \mu \mathrm{M})$ pretreatment. (D) Immunoblots from Ad-GFP- (200 MOI) or Ad-PTEN- (200 MOI) infected Huh7 cells treated with $\mathrm{PGE}_{2}(1 \mu \mathrm{M})$ for $48 \mathrm{~h}$. (E) Effect of rapamycin $(100 \mathrm{nM})$ on spheres formation in N1-S1 and Huh7 cells with or without $\mathrm{PGE}_{2}$ pretreatment. $\left({ }^{*} p<0.05, * * p<0.01\right)$. 
was involved in celecoxib-induced suppression of hepatic cancer stemness. Moreover, celecoxib has been reported to stimulate PPAR $\gamma$ as well as PTEN, the endogenous antagonist of Akt signaling, in hepatoma cells [20], we investigated whether this signaling pathway affects the therapeutic mechanism of celecoxib for Novikoff hepatoma. Immunoblot analysis revealed that expression of PPAR $\gamma$ and PTEN was significantly upregulated as well as Akt was dephoshorylated in celecoxib-treated hepatoma tissues (Fig. 5A). Likewise, immunofluorescence analysis revealed the prominent increase in PPAR $\gamma$ and PTEN expression in celecoxib-treated N1-S1 cells (Fig. 5B). Immunoblot analysis further showed that celecoxib-elicited PPAR $\gamma /$ PTEN upregulation and Akt dephosphorylation were dose-dependent (Fig. 5C).

Pharmaceutical modulators of PPAR $\gamma$ signaling were used to confirm the role of PPAR $\gamma$ in celecoxibinduced PTEN upregulation in hepatoma cells. Treatment

with rosiglitazone, a PPAR $\gamma$ agonist, increased the endogenous and celecoxib-induced PTEN protein levels in hepatoma cells (Fig.5D). In contrast, adding GW9662, a PPAR $\gamma$ antagonist, attenuated celecoxib-induced PTEN upregulation without affecting the basal PTEN levels (Fig. 5E).

To validate whether PTEN upregulation indeed contributed to the inhibition of hepatic cancer stemness and hepatoma growth, we employed adenovirus gene delivery to achieve PTEN overexpression in hepatoma cells. It was found that PTEN-overexpressing N1-S1 cells not only showed attenuated Akt phosphorylation, but also diminished CD133 and CD44 expression (Fig. 6A). In animal study, Ad-PTEN-infected N1-S1 cells did not led to hepatoma formation in rats $(0 / 8)$, which whereas was lower than tumor incidence in Ad-GFP (6/8) and control (6/8) groups (Fig. 6B). Moreover, we also found that Ad-PTEN gene delivery suppressed $\mathrm{PGE}_{2}$-promoted

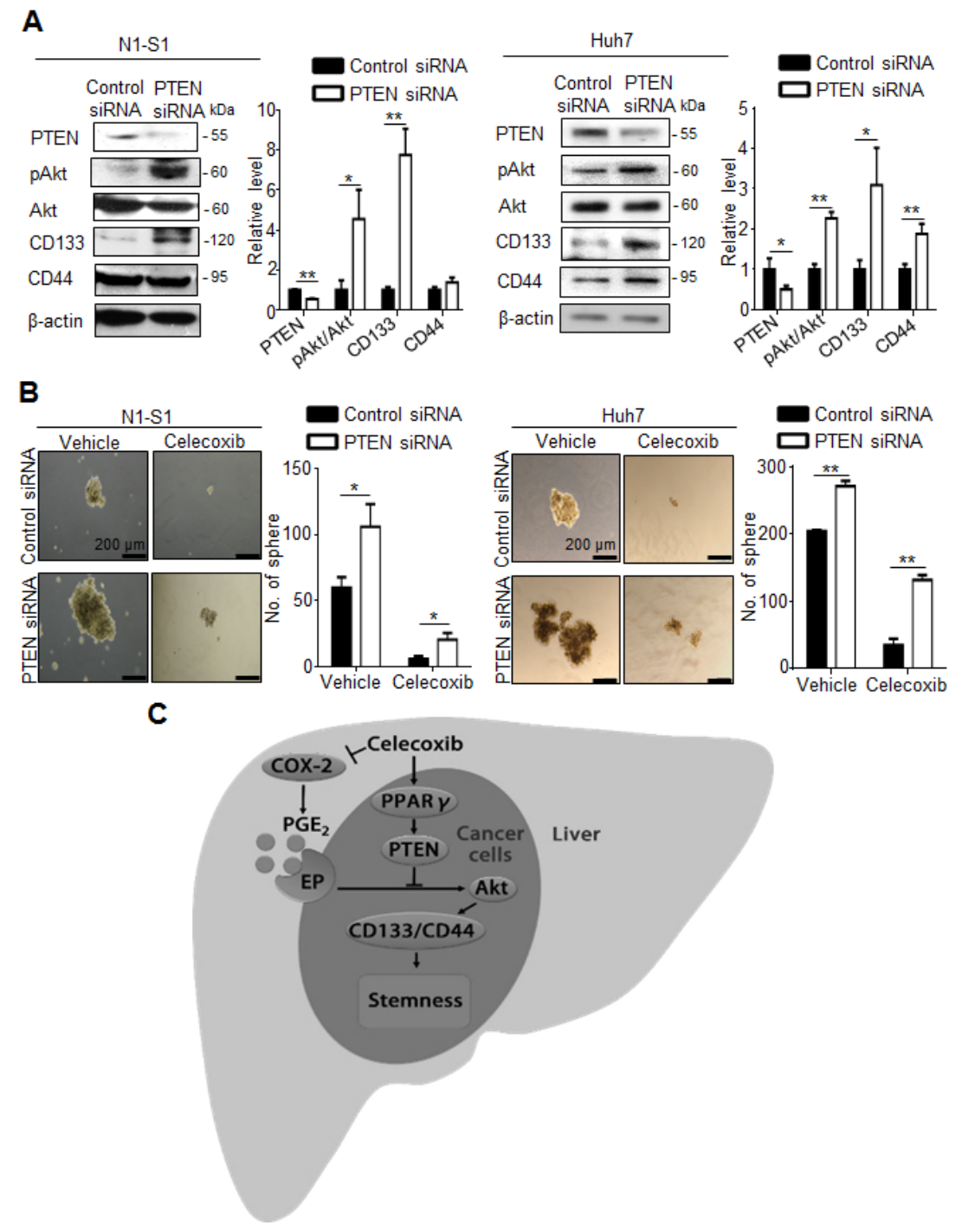

Fig 7: PTEN knockdown attenuates the effect of celecoxib on stemness. (A) Immunoblot analysis in N1-S1 (left panel) and Huh7 (right panel) cells after siRNA transfection for $72 \mathrm{~h}$. (B) Effect of celecoxib on spheres formation in control siRNA-trasfected- or PTEN siRNA-transfected- N1-S1 (left panel) and Huh7 cells (right panel). (C) The proposed mechanism for celecoxib-induced inhibition of hCSCs. $(* p<0.05, * * p<0.01)$. 
sphere formation in human Huh-7 cells (Fig. 6C). In immunoblot analysis, PTEN overexpression also reversed $\mathrm{PGE}_{2}$-induced Akt activation and hCSCs marker upregulation in Huh7 cells (Fig. 6D). Because mammalian target of rapamycin (mTOR) is downstream effector of Akt, we utilized rapamycin, a mTOR inhibitor, and found rapamycin also suppressed $\mathrm{PGE}_{2}$-stimulated sphere formation in hepatoma cells (Fig. 6E). To validate the role of PTEN in celecoxib-mediated stemness inhibition, PTEN knockdown was performed using PTEN siRNA, which significantly increased the expression of CD133 and CD44 (Fig. 7A), and enhanced the cancer stemness in hepatoma cells in HCC cells (Fig. 7B). Besides, PTEN silencing significantly attenuated the anti-stemness effect of celecoxib in N1-S1 cells (from $90.50 \%$ inhibition to $80.82 \%$ inhibition; $p<0.05$ ) and Huh7 cells (from $82.84 \%$ inhibition to $51.41 \%$ inhibition; $p<0.01$ ) cells. These results indicate PPAR $\gamma / \mathrm{PTEN} /$ Akt signaling plays a crucial role in celecoxib-induced suppression of cancer stemness and hepatoma progression.

\section{DISCUSSION}

The present study demonstrates for the first time that celecoxib is a potent inhibitor of cancer stemness in $\mathrm{HCC}$ in vitro and in vivo. This is consistent with a recent study that celecoxib inhibits tumor sphere through CD133 downregulation in colon cancer [28]. Importantly, the anti-CSCs function of celecoxib could not be reversed by exogenous $\mathrm{PGE}_{2}$ supply, implicating COX-2/PGE - -independent pathway might be involved in celecoxib-induced stemness suppression. This is in accordance with previous studies showing COX2-dependent and COX-2-independent mechanism in celecoxib-mediated inhibition of HCC growth $[19,20]$. However, celecoxib alone inhibited the stemness-related function without affecting the $\mathrm{CD} 44^{+} / \mathrm{CD} 133^{+} \mathrm{hCSCs}$, implicating additional hCSC population were regulated by celecoxib. We next validated whether $\mathrm{PGE}_{2}$-promoted and celecoxib-inhibited self-renewal were through the regulation of hCSCs surface markers in N1-S1 cells. CD133 over-expression significantly promoted the sphere formation, but the stimulatory effect of $\mathrm{PGE}_{2}$ on sphere formation could not be observed in CD133-overexpressing hepatoma cells, suggesting that CD133 up-regulation participated in $\mathrm{PGE}_{2}$-induced cancer stemness. However, CD133 overexpression failed to rescue celecoxib-induced suppression of sphere formation, implicating CD133 is might be a relatively downstream effector in celecoxibinduced stemness inhibition. Together, CD133 downregulation contributed to celecoxib-induced suppression of $\mathrm{PGE}_{2}$-stimulated cancer stemness.

$\mathrm{COX}-2 / \mathrm{PGE}_{2}$ signaling regulates liver regeneration [29] and stem cells [25], and signal regulation and the pathway are similar for normal and cancer stem cells [30]. $\mathrm{COX}-2 / \mathrm{PGE}_{2}$ signaling can promote cancer stemness in colon cancer [31, 32], breast cancer [33] and leukemia [34]. COX-2 can promotes HCC cell growth through Akt activation [8], but the role of COX-2/ $\mathrm{PGE}_{2}$ signaling in hepatic cancer stemness has not yet been reported. In this study, exogenous or non-tumor derived $\mathrm{PGE}_{2}$ promoted tumor sphere formation and increment of SPCs and $\mathrm{CD} 44^{+} / \mathrm{CD} 133^{+}$hCSCs in $\mathrm{HCC}$ cells. It has been reported that $\mathrm{PGE}_{2}$ can promote Akt signaling [9], and Akt signaling also involved in $\mathrm{CD}_{133^{+}}$hCSCs regulaton [16]. From upon evidences, non-tumor COX-2 can be as a target for cancer therapy and prevention in advanced HCC.

Recently, lupeol, a triterpene from fruits and vegetables, inhibited the self-renewal ability of liver tumor-initiating cells (TICs) present in both HCC cell lines and clinical HCC samples. Besides, PTEN upregulation participates in lupeol-induced inhibition of CD133 expression, self-renewal and chemoresistance in hepatoma cells [23]. It also been reported that NSAIDs suppress cancer stem cells via inhibiting COX-2 and activating PPAR $\gamma$ in colon cancer [35]. Celecoxib also up-regulates PPAR $\gamma$ and PTEN, and PTEN is a negative regulator of Akt activity. It has been reported that celecoxib increases PPAR $\gamma$ expression and PTEN activity in wild-type and COX-2-deleted Huh7 cells [20]. Besides, two putative PPAR $\gamma$ binding sites within the PTEN promoter are present approximately 15 and $13 \mathrm{~kb}$ upstream of the ATG site [36]. In our study, rosiglitazone enhanced celecoxibinduced up-regulation of PTEN in N1-S1 cells, and GW9662 attenuated celecoxib-induced up-regulation of PTEN. This indicates that celecoxib can up-regulate PTEN mediated activation and up-regulation of PPAR $\gamma$ in hepatoma cells. Liver specific PTEN deletion promotes CD133 ${ }^{+}$hCSCs in mice [37], and knockdown of PTEN can up-regulate CD133 expression in hepatoma cells [23]. We also found Ad-PTEN gene delivery suppressed hCSCs marker expression and tumor initiating, and PTEN knockdown up-regulated CD133 and CD44 in hepatoma cells. In human Huh-7 cells, Ad-PTEN gene delivery suppressed $\mathrm{PGE}_{2}$-induced Akt activation, CD133/CD44 up-regulation and tumor sphere formation. PTEN siRNA transfection partially prevented the effect of celecoxib on sphere formation in N1-S1 and Huh7 cells. This indicates celecoxib-induced PTEN up-regulation is partially involved in the suppression of hepatic cancer stemness. PTEN is not only upstream regulator of Akt, recent studies indicated other molecular such as Aurora A also regulate Akt pathway [38]. mTOR (a downstream effector of Akt) is also highly activated in aggressive HCC, and mTOR activation plays an important role in hepatoma cell growth and development [39]. We also found rapamycin (mTOR inhibitor) suppressed tumor sphere in Huh7 cells. Moreover, PTEN/Akt signaling is also involved in $\mathrm{CD}_{4} 4^{+}$ $\mathrm{CD} 133^{+} \mathrm{CSCs}$ in other solid tumors, not only in liver cancer [40]. Rapamycin also suppressed sphere formation in other cancer [41].

In chemoprevention studies, a 17-day celecoxib 
treatment potently suppressed tumor burden and tumor weight in rats with Novikoff hepatoma. This is consistent with a previous study showing that diethylnitrosamine induced HCC [18]. Additionally, a preventive celecoxib regimen inhibits CD44 and CD133 expression. Therapeutic celecoxib can retard tumor growth and inhibit $\mathrm{CD}_{4} 4^{+} / \mathrm{CD}_{133^{+}}$hCSCs. Moreover, CD $133^{+} \mathrm{CSCs}$ reportedly differentiate into endothelial cells in tumors [27]. We also found that celecoxib therapy decreased $\mathrm{CD} 31^{+} / \mathrm{CD} 133^{+}$blood vessels in tumor tissues, indicating the trans-differentiation potential of hCSCs. Suppression of hCSCs may be involved in the inhibition of cell proliferation and angiogenesis, as well as induction of cell apoptosis in vivo following celecoxib therapy. hCSCs and tumor microenvironments interaction is very important in HCC progression [42], and cancer stemness also promotes immunosppressive cells infiltration (tumor-associated macrophages and regulatory $\mathrm{T}$ cells) $[43,44]$. Immunecompetent orthotopic HCC model can provide a truest stemness niches and tumor microenvironments, and it is an advantage in stem cells biology and tumor immunology studies. In this study, the dose and duration of celecoxib therapy required to suppress cancer stemness is clinically feasible because the pharmacokinetic of celecoxib indicates that the serum celecoxib levels can reach up to $10 \mu \mathrm{M}$ in rats after feeding at $30 \mathrm{mg} / \mathrm{kg}$ [45]. Moreover, it has been recently reported that a 3-day treatment was sufficient to downregulate CD133 expression in patients with colon cancer [46]. This again supports that the dosage of celecoxib used in our study is in the range of physiological concentration, and celecoxib treatment for 7 days is sufficient for suppressing an increase in hCSCs during the short-term therapy. Given the lack of hepatotoxicity and bone marrow suppression, celecoxib therapy may constitute an adjuvant therapy for current HCC therapeutic modalities. Although celecoxib therapy fails to eradicate established $\mathrm{HCC}$, further investigation examining the potential of celecoxib as adjuvant therapy for current HCC therapies such as surgery, TAE, target therapy or chemotherapy is expected, particularly because celecoxib is well tolerated in humans and shows an excellent safety record and limited hepatic toxicity [47]. MK-2206 (a Akt inhibitor) has been reported that it can synergize with convention chemotherapy in HCC [48]. Celecoxib inhibited Akt activation in this study, celecoxib and chemotherapeutic drug combined therapy is maybe a potential treatment for $\mathrm{HCC}$ in future. Liver fibrosis/ cirrhosis is often observed in HCC patients, celecoxib also shows antifibrogenic effects in rats $[49,50]$, implicating celecoxib should be considered to treat HCC or other liver diseases in future.

We herewith proposed a model for celecoxibmediated inhibition of hCSC expansion in Novikoff hepatoma (Fig. 7C). In the extrinsic pathway, celecoxib reduces $\mathrm{PGE}_{2}$ production by inhibiting the activities of COX-2 in inflammatory non-tumor tissues In the intrinsic pathways, celecoxib activates the PPAR $\gamma / \mathrm{PTEN}$ pathway, leading to perturbation of the $\mathrm{PGE}_{2}$-stimulated Akt signaling. Because of such a dual function of celecoxib in modulating cancer stemness, the therapeutic efficacy of celecoxib for rat Novikoff hepatoma. Because of its similar potency in repressing cancer stemness in human $\mathrm{HCC}$, our study advocates that celecoxib may be constitute an alternative therapeutic agent in human HCC.

In conclusion, we found that celecoxib therapy inhibits hCSCs expansion through both extrinsic and intrinsic pathways; we identified a novel pathway for Aktsignaling regulation by PPAR $\gamma / \mathrm{PTEN}$, which involved, in part, the intrinsic pathway regulating hCSCs. This is the first study to evaluate the therapeutic efficacy and survival analysis of celecoxib in orthotopic HCC. Celecoxib shows a high potential for use in a monotherapy or adjuvant therapy for treating HCC. Because limited therapeutic options are available for treating $\mathrm{HCC}$, celecoxib or COX-2 inhibitors may present a promising alternative for treating HCC. Future clinical studies are necessary to validate the therapeutic potential of celecoxib for HCC and other aggressive cancers.

\section{MATERIALS AND METHODS}

\section{Cell culture and drugs}

N1-S1 (rat HCC), Clone-9 (rat hepatocyte), Hep3B (human HCC) and Huh7 (human HCC) cells were from American Type Culture Collection (ATCC) where they were characterized by mycoplasma detection, DNA Fingerprinting, isozyme detection and cell vitality detection. All cell lines were immediately expanded and frozen such that they could be restarted every 2 to 3 months from a frozen vial of the same batch of cells. $\mathrm{N} 1-\mathrm{S} 1$ cells were maintained in RPMI-1640 medium (Gibco, Bethesda, MD) containing 10\% calf serum (Hyclone). Clone-9 cells were maintained in $\mathrm{F} 12 \mathrm{~K}$ medium (Gibco, Bethesda, MD) containing 10\% fetal bovine serum (Hyclone). Hep3B and Huh7 cells were maintained in DMEM medium (Gibco, Bethesda, MD) containing $10 \%$ calf serum. All the media for cell culture were supplemented with $2 \mathrm{mM}$ l-glutamine (Hyclone), $100 \mathrm{mg} / \mathrm{mL}$ streptomycin (Hyclone), and $100 \mathrm{U} / \mathrm{mL}$ penicillin (Hyclone). All cells were maintained under humidified conditions in $95 \%$ air and $5 \% \mathrm{CO}_{2}$ at $37^{\circ} \mathrm{C}$. Celecoxib powder was from Pharmacia Corp (St. Louis, MO). Celecoxib capsules (200 mg tablets; Celebrex) were purchased from Pfizer (La Jolla, CA). GW9662, rosiglitazone, verapamil, and rapamycin were purchased from Sigma (St. Louis, MO). $\mathrm{PGE}_{2}$ was purchased from Merck (Darmstadt, Germany). 


\section{Cell proliferation Assay}

To access the growth rates, cells $\left(5 \times 10^{3} /\right.$ well) were seeded in 96-well plates, and then cells were incubated overnight in $95 \%$ air and $5 \% \mathrm{CO}_{2}$ at $37^{\circ} \mathrm{C}$ before drug treatment. After drug treatment for 48 hours, Alarmar Blue reagent (10:1) (Invitrogen) was added and cells were incubated at $37^{\circ} \mathrm{C}$ for 2 hours. Absorbance was measured with an ELISA reader (Dynex Technologies, Inc., Chantilly, VA) at 570-600 $\mathrm{nm}$. Cell viability was expressed as a percentage of absorbance in treated wells relative to that of untreated (control) wells.

\section{Colony formation assay}

Hep3B and Huh7 cells (3000 cells per well) were treated with celecoxib for 10 days, and cells were stained with crystal violet and aggregates of more than 50 cells were scored as colonies.

\section{Real-time quantitative RT-PCR}

Total RNA was extracted from cultured cells using Trizol (Tel-Test Inc., Friendswoods, TX). Two micrograms of total RNA was used for the reverse transcription reaction with Superscriptase II (Invitrogen, Carlsbad, CA) using oligo-dT and random primers. One twentieth of complementary DNA generated was used as template for real time PCR analysis. Amplification and detection were done by a LightCycler DNA Master SYBR Green I kit (Roche, Manheim, Germany) in a LightCycler Detection System (Roche, Manheim, Germany). The PCR reaction was carried out as follows: one cycle of $95^{\circ} \mathrm{C}$ for $10 \mathrm{~min}$, 45 cycles of $95^{\circ} \mathrm{C}$ for $15 \mathrm{~s}, 60^{\circ} \mathrm{C}$ for $5 \mathrm{~s}$, and $72{ }^{\circ} \mathrm{C}$ for 20 s. After amplification, a final melting curve protocol was performed to determine the specificity of the PCR reaction. The primer sequences were as follows: $\beta$-actin, (forward primer: 5'-TCCTGTGGCATCCACGAAACT-3'; reverse primer: 5'-GAAGCATTTGCGGTGGACGAT-3'); COX-2, (forward primer: 5'-GGTGTATCCCCCCACAGTCA-3'; reverse primer: 5'-CCAGG CACCAGACCAAAGAC-3').

\section{PGE2 quantification:}

Measurement of secreted $\mathrm{PGE}_{2}$ in culture supernatant was done by competitive enzyme immunoassay (EIA) kit (Cayman Chemical, Ann Arbor, $\mathrm{MI})$.

\section{Sphere formation assay}

N1-S1 or Huh7 cells were suspended in serum-free stem cell medium containing DMEM/F12 supplemented with N2 supplement (Gibco), EGF (20 ng/mL; PeproTech), and bFGF (20 ng/mL; PeproTech). To study the effect of celecoxib or rapamycin on $\mathrm{PGE}_{2}$-promoted sphere formation, cells were pretreated with $\mathrm{PGE}_{2}(1 \mu \mathrm{M})$ in serum-free medium for $48 \mathrm{~h}$ after serum starvation for $24 \mathrm{~h}$. After PGE 2 pretreatment, cells (5000 cells per well) were seeded into an ultralow-attachment 6-well plate (Corning Life Sciences, Lowell, MA) with or without celecoxib $(10 \mu \mathrm{M})$ or rapamycin $(100 \mathrm{nM})$ treatment. After 7 to 10 days, the number of tumor spheres was evaluated using light microscopy (Leica Microsystems). When cells were infected with adenovirus (Ad-GFP or Ad-PTEN), $\mathrm{PGE}_{2}(1 \mu \mathrm{M})$ was added at $12 \mathrm{~h}$ post infection, and cells were treated in serum-free medium for $48 \mathrm{~h}$ before sphere culture. When cells were transfected with siRNA, cells were seeded into an ultralow-attachment 6-well plate with or without celecoxib $(10 \mu \mathrm{M})$ at $12 \mathrm{~h}$ post transfection.

\section{Side population cells (SPCs) analysis}

After treatment with celecoxib $(10 \mu \mathrm{M})$ or $\mathrm{PGE}_{2}(1$ $\mu \mathrm{M})$ in serum-free medium for 48 hours, cells $\left(1 \times 10^{6}\right.$ cells $/ \mathrm{mL}$ ) were incubated in DMEM $/ 5 \%$ FBS containing fresh Hoechst 33342 (final concentration $5 \mu \mathrm{g} / \mathrm{mL}$; Sigma-Aldrich) for $90 \mathrm{~min}$ at $37^{\circ} \mathrm{C}$. In some cases, cells were incubated with the Hoechst dye in the presence of verapamil $(50 \mu \mathrm{M}$; Sigma-Aldrich) for reliable gating of SPCs. After indicated treatment, cells were centrifuged and resuspended in PBS containing propidium iodide (1 $\mu \mathrm{g} / \mathrm{mL}$; Sigma-Aldrich) for $5 \mathrm{~min}$ before flow cytometric analysis (Becton Dickinson). The Hoechst dye was excited with the UV laser at 351-364 nm, and fluorescence was measured using a 515-nm side population filter (Hoechst blue) and a 608 EFLP optical filter (Hoechst red). A 540 DSP filter was used to separate the emission wavelengths. Data were collected and analyzed using the CellQuest software (Becton Dickinson).

\section{Retrovirus production and infection}

Retrovirus vectors encoding CD133 was generated by co-transfection of pCX-puro-CD133 with pVSV-G (envelope) and pVSV-GP (packaging) plasmids in 293T cells using lipfectamine 2000 (Invitrogen). N1-S1 cells were infected with virus-containing medium for 24 hours and stable expression clones were selected with $2 \mu \mathrm{g} / \mathrm{ml}$ puromycin (Invitrogen) for 7 days.

\section{Immunoblot analysis}

Protein was isolated using buffer containing 150 $\mathrm{mM} \mathrm{NaCl}, 50 \mathrm{mM}$ HEPES, $\mathrm{pH}$ 7, 1\% Triton X-100, 10\% glycerol, $1.5 \mathrm{mM} \mathrm{MgCl}, 1 \mathrm{mM}$ EGTA, and protease inhibitors (Roche, Mannheim, Germany). After the 
proteins were separated using 8\%- 10\% SDS-PAGE, they were transferred onto polyvinylidene fluoride membranes by using a blotting apparatus. The membrane was blocked with 5\% milk in Tris-buffered saline/Tween-20 for $1 \mathrm{~h}$ and then incubated with a 1:500 dilution of CD44, CD133, Akt, ALDH, VEGF, PPAR $\gamma$, HA-tag or GFP antibody (all from Santa Cruz Biotechnology); a 1:1000 dilution of pAkt (ser473), PTEN, or PCNA antibody (all from Cell Signaling, Beverly, MA); a 1:5000 dilution of $\beta$-actin antibody (Sigma-Aldrich) for $1 \mathrm{~h}$ at room temperature or overnight at $4{ }^{\circ} \mathrm{C}$. After the secondary antibody was conjugated with HRP (1:5000 dilution in 5\% milk; Santa Cruz Biotechnology) for $60 \mathrm{~min}$, the signals on the membrane were detected using ECL-Plus luminol solution (GE Healthcare, Little Chalfont, Buckinghamshire, UK) and exposed to X-ray film for autoradiography. Quantification was performed using the Quantity-One software (Bio-Rad Laboratories, Hercules, CA).

\section{Animal experiments}

All experimental procedures were reviewed and approved by the Institutional Animal Care and Use Committee before the study began, and we ensured that all animals received humane care and that study protocols complied with the institution's guidelines. The US-guided induction of Novikoff hepatoma in Sprague Dawley (SD) rats was performed as previously described [21]. In chemopreventive regimen, rats $(n=12)$ were implanted with N1-S1 cells on day 0 , then divided into two groups receiving saline $(\mathrm{n}=6)$ or celecoxib $(30 \mathrm{mg} / \mathrm{kg} / \mathrm{day} ; \mathrm{n}$ =6) via oral route for 17 days, and sacrificed on day 18 for histological analysis. For therapeutic studies, rats (n =32) were implanted with N1-S1 cells on day 0. After confirming HCC formation by US monitoring on day 10 , rats $(\mathrm{n}=26)$ were divided into two groups receiving saline $(\mathrm{n}=13)$ or celecoxib $(30 \mathrm{mg} / \mathrm{kg} /$ day; $\mathrm{n}=13)$ via oral route for additional 7 days, and sacrificed on day 18 for histological analysis. For survival analysis, rats $(\mathrm{n}=$ 24) were used for induction of Novikoff hepatoma on day 0 . After confirming HCC formation by US monitoring on day 10 , rats $(\mathrm{n}=18)$ were divided into two groups receiving saline $(\mathrm{n}=9)$ or celecoxib $(30 \mathrm{mg} / \mathrm{kg} / \mathrm{day} ; \mathrm{n}=$ 9) via oral route for additional 60 days. In adenovirus gene delivery study, N1-S1 cells were infected with adenovirus vectors at a multiplicity of infection (MOI) of 200 for 24 $\mathrm{h}$, implanted into rat under US guidance on day 0 . The hepatoma induction was determined after day 10 .

\section{Histological analysis}

For immunohistochemical analysis, paraffinembedded hepatoma tissue blocks were sectioned into 3 - $\mu$ m-thick slices and mounted on poly(lysine)-coated slides. After the slides were deparaffinized, they were blocked with $3 \%$ hydrogen peroxide for $10 \mathrm{~min}$ and subjected to antigen retrieval in $10 \mathrm{mM}$ citrate buffer for $15 \mathrm{~min}$ in a microwave. The slides were incubated with a 1:50 dilution of CD31, CD133 or CD44 antibody (all from Santa Cruz Biotechnology, Santa Cruz, CA); or a 1:50 dilution of Ki-67 antibody (Cayman Chemical, Ann Arbor, MI) at $4{ }^{\circ} \mathrm{C}$ overnight. After the sections were washed with PBS, they were incubated with horseradish peroxidase/Fab polymer conjugate (polymer detection system; Zymed Laboratories, South San Francisco, USA) for $30 \mathrm{~min}$ and detected using diaminobenzidine (1:20 dilution; Zymed Laboratories, South San Francisco, USA). For immunofluorescence detection of CD31, CD133, and CD44 in a paraffin-embedded hepatoma section of $\mathrm{HCC}$, protein blocking was performed for $30 \mathrm{~min}$ in $10 \%$ fetal calf serum after antigen retrieval in $10 \mathrm{mM}$ citrate buffer for $15 \mathrm{~min}$ in a microwave. CD31, CD133, and CD44 antibodies (1:50 dilution for all; Santa Cruz Biotechnology) were applied to the sections, which were then incubated at room temperature for $2 \mathrm{~h}$, followed by repeated washing with phosphate-buffered saline (PBS). Next, tissue sections were incubated with Alexa Fluor 546or Alexa Fluor 488-conjugated IgG (Molecular Probes, Eugene, OR) for $30 \mathrm{~min}$ at room temperature. After the slides were mounted in mounting media (Dako, Glostrup, Denmark), they were visualized under a fluorescence microscope (Leica Microsystems, Schweiz, AG-CH).

\section{Counting of $\mathrm{CD}^{+} / \mathrm{CD}^{+33}{ }^{+}$hCSCs by flow cytometry}

After $10 \mu \mathrm{M}$ celecoxib or $1 \mu \mathrm{M} \mathrm{PGE}_{2}$ treatment in serum-free medium for 48 hours, cells were incubated with CD44 and CD133 (1:100 dilution for both; both were from Santa Cruz Biotechnology) antibodies for 30 min at room temperature and then washed 3 times with PBS. Next, signals were detected using an Alexa Fluor 488- or 546-conjugated IgG (Molecular Probes). Then, we used FACS Calibur flow cytometry (Becton Dickinson, San Jose, CA) to determine the ratio of CD $44^{+} / \mathrm{CD} 133^{+}$ hCSCs. All the data were collected and analyzed using the CellQuest software (Becton Dickinson).

\section{Cell immunofluorescence analysis}

After $10 \mu \mathrm{M}$ celecoxib or vehicle treatment for 48 hours, cells were fixed in 4\% paraformaldehyde for $10 \mathrm{~min}$ and stained with PPAR $\gamma$, and PTEN antibodies (1:50 dilution for all; all the antibodies were from Santa Cruz Biotechnology), followed by an Alexa Fluor 488 or 546-conjugated IgG (Molecular Probes). The cells were counterstained with DAPI and visualized using a confocal microscope (Carl Zeiss, Jena, Germany). Quantification was performed using the ImageJ software (NIH). 


\section{Terminal deoxynucleotidyl transferase-mediated dUTP nick end-labeling (TUNEL) staining}

Rat hepatoma sections were placed on slides, deparaffinized, and washed with PBS. TUNEL analysis was performed using the in situ Cell Death Detection Kit, Fluorescein (Roche, Indianapolis, IN), according to the manufacturer's protocol. TUNEL-positive cells were visualized using immunofluorescent microscopy and counted using a $20 \times$ objective. TUNEL-positive cells containing FITC were identified by colocalization with 4,6-diamidino-2-phenylindole (DAPI) staining and on the basis of morphological features. More than 100 cells were counted for each variable per experiment. The slides were viewed under a fluorescence microscope (Leica Microsystems), with green fluorescence set at $520 \mathrm{~nm}$. The cells that were stained green indicated apoptotic cells. For comparison, the amount of positive staining was counted under low power fields.

\section{Adenovirus production and infection}

Production and infection of adenovirus vectors were performed as previously described [51].

\section{Transfection with siRNA}

N1-S1 cells (in 6-well plate) were transfected with scramble siRNA and PTEN siRNA (Santa Cruz Biotechnology, Santa Cruz, CA) for 72 hours using the lipofectamine 2000 (Invitrogen, Carlsbad, CA) according to the manufacturer's instructions.

\section{Statistical Analysis}

Differences between the groups were statistically evaluated using the unpaired Student's $t$ test. Survival analysis was performed using the Kaplan-Meier method in SPSS V.19 software. Data were mean \pm SD. All $P$ values were two-tailed $\left({ }^{*} p<0.05, * * p<0.01\right)$.

\section{Competing interests:}

None related to the content of this article.

\section{Financial support:}

This work was supported by grants from the National Science Council, Taiwan (NSC 100-2325-B-110002-MY3 and NSC-100-2321-B-110-004 to Ming-Hong Tai), Kaohsiung Veterans General Hospital, Taiwan (VGHKS99-021 to Hoi-Hung Chan and VGHKS100-025 to E-Ming Wang) and National Sun Yat-Sen University.

\section{REFERENCES}

1. El-Serag HB. Hepatocellular carcinoma: an epidemiologic view. J Clin Gastroenterol. 2002; 35(5 Suppl 2):S72-78.

2. Poon D, Anderson BO, Chen LT, Tanaka K, Lau WY, Van Cutsem E, Singh H, Chow WC, Ooi LL, Chow P, Khin MW and Koo WH. Management of hepatocellular carcinoma in Asia: consensus statement from the Asian Oncology Summit 2009. Lancet Oncol. 2009; 10(11):1111-1118.

3. Llovet JM and Bruix J. Molecular targeted therapies in hepatocellular carcinoma. Hepatology. 2008; 48(4):13121327.

4. Cervello M, McCubrey JA, Cusimano A, Lampiasi N, Azzolina A and Montalto G. Targeted therapy for hepatocellular carcinoma: novel agents on the horizon. Oncotarget. 2012; 3(3):236-260.

5. Cervello $M$ and Montalto G. Cyclooxygenases in hepatocellular carcinoma. World J Gastroenterol. 2006; 12(32):5113-5121.

6. Kondo M, Yamamoto $\mathrm{H}$, Nagano H, Okami J, Ito $\mathrm{Y}$, Shimizu J, Eguchi H, Miyamoto A, Dono K, Umeshita K, Matsuura N, Wakasa K, Nakamori S, Sakon M and Monden $\mathrm{M}$. Increased expression of COX-2 in nontumor liver tissue is associated with shorter disease-free survival in patients with hepatocellular carcinoma. Clinical cancer research : an official journal of the American Association for Cancer Research. 1999; 5(12):4005-4012.

7. Kern MA, Schubert D, Sahi D, Schoneweiss MM, Moll I, Haugg AM, Dienes HP, Breuhahn K and Schirmacher P. Proapoptotic and antiproliferative potential of selective cyclooxygenase-2 inhibitors in human liver tumor cells. Hepatology. 2002; 36(4 Pt 1):885-894.

8. Leng J, Han C, Demetris AJ, Michalopoulos GK and Wu T. Cyclooxygenase-2 promotes hepatocellular carcinoma cell growth through Akt activation: evidence for Akt inhibition in celecoxib-induced apoptosis. Hepatology. 2003; 38(3):756-768.

9. $\mathrm{Lu} \mathrm{D}$, Han $\mathrm{C}$ and $\mathrm{Wu} \mathrm{T}$. Microsomal prostaglandin E synthase-1 promotes hepatocarcinogenesis through activation of a novel EGR1/beta-catenin signaling axis. Oncogene. 2012; 31(7):842-857.

10. Reya T, Morrison SJ, Clarke MF and Weissman IL. Stem cells, cancer, and cancer stem cells. Nature. 2001; 414(6859):105-111.

11. Majumdar A, Curley SA, Wu X, Brown P, Hwang JP, Shetty K, Yao ZX, He AR, Li S, Katz L, Farci P and Mishra L. Hepatic stem cells and transforming growth factor beta in hepatocellular carcinoma. Nat Rev Gastroenterol Hepatol. 2012; 9(9):530-538.

12. Ma S, Chan KW, Hu L, Lee TK, Wo JY, Ng IO, Zheng $\mathrm{BJ}$ and Guan XY. Identification and characterization of tumorigenic liver cancer stem/progenitor cells. Gastroenterology. 2007; 132(7):2542-2556.

13. Ma S, Chan KW, Lee TK, Tang KH, Wo JY, Zheng BJ 
and Guan XY. Aldehyde dehydrogenase discriminates the CD133 liver cancer stem cell populations. Mol Cancer Res. 2008; 6(7):1146-1153.

14. Zhu Z, Hao X, Yan M, Yao M, Ge C, Gu J and Li J. Cancer stem/progenitor cells are highly enriched in CD133+CD44+ population in hepatocellular carcinoma. International journal of cancer Journal international du cancer. 2010; 126(9):2067-2078.

15. Yang XR, Xu Y, Yu B, Zhou J, Qiu SJ, Shi GM, Zhang BH, Wu WZ, Shi YH, Wu B, Yang GH, Ji Y and Fan J. High expression levels of putative hepatic stem/progenitor cell biomarkers related to tumour angiogenesis and poor prognosis of hepatocellular carcinoma. Gut. 2010; 59(7):953-962.

16. Ma S, Lee TK, Zheng BJ, Chan KW and Guan XY. CD133+ HCC cancer stem cells confer chemoresistance by preferential expression of the Akt/PKB survival pathway. Oncogene. 2008; 27(12):1749-1758.

17. You H, Ding W, Dang H, Jiang Y and Rountree CB. c-Met represents a potential therapeutic target for personalized treatment in hepatocellular carcinoma. Hepatology. 2011; 54(3):879-889.

18. Marquez-Rosado L, Trejo-Solis MC, Garcia-Cuellar $\mathrm{CM}$ and Villa-Trevino S. Celecoxib, a cyclooxygenase-2 inhibitor, prevents induction of liver preneoplastic lesions in rats. J Hepatol. 2005; 43(4):653-660.

19. Cui $\mathrm{W}, \mathrm{Yu} \mathrm{CH}$ and $\mathrm{Hu} \mathrm{KQ}$. In vitro and in vivo effects and mechanisms of celecoxib-induced growth inhibition of human hepatocellular carcinoma cells. Clinical cancer research : an official journal of the American Association for Cancer Research. 2005; 11(22):8213-8221.

20. Cui W, Hu SX, Tang ZY and Hu KQ. In-vivo effects and mechanisms of celecoxib-reduced growth of cyclooxygenase-2 (COX-2)-expressing versus COX-2deleted human HCC xenografts in nude mice. Anti-cancer drugs. 2008; 19(9):891-897.

21. Chan HH, Chu TH, Chien HF, Sun CK, Wang EM, Pan HB, Kuo HM, Hu TH, Lai KH, Cheng JT and Tai MH. Rapid induction of orthotopic hepatocellular carcinoma in immune-competent rats by non-invasive ultrasound-guided cells implantation. BMC Gastroenterol. 2010; 10:83.

22. Koga H, Sakisaka S, Ohishi M, Kawaguchi T, Taniguchi E, Sasatomi K, Harada M, Kusaba T, Tanaka M, Kimura R, Nakashima Y, Nakashima O, Kojiro M, Kurohiji $\mathrm{T}$ and Sata M. Expression of cyclooxygenase-2 in human hepatocellular carcinoma: relevance to tumor dedifferentiation. Hepatology. 1999; 29(3):688-696.

23. Lee TK, Castilho A, Cheung VC, Tang KH, Ma S and $\mathrm{Ng}$ IO. Lupeol targets liver tumor-initiating cells through phosphatase and tensin homolog modulation. Hepatology. 2011; 53(1):160-170.

24. Hu C, Li H, Li J, Zhu Z, Yin S, Hao X, Yao M, Zheng S and $\mathrm{Gu}$ J. Analysis of ABCG2 expression and side population identifies intrinsic drug efflux in the HCC cell line MHCC-
97L and its modulation by Akt signaling. Carcinogenesis. 2008; 29(12):2289-2297.

25. Goessling W, North TE, Loewer S, Lord AM, Lee S, Stoick-Cooper CL, Weidinger G, Puder M, Daley GQ, Moon RT and Zon LI. Genetic interaction of PGE2 and Wnt signaling regulates developmental specification of stem cells and regeneration. Cell. 2009; 136(6):1136-1147.

26. Eisenhauer EA, Therasse P, Bogaerts J, Schwartz LH, Sargent D, Ford R, Dancey J, Arbuck S, Gwyther S, Mooney M, Rubinstein L, Shankar L, Dodd L, Kaplan R, Lacombe D and Verweij J. New response evaluation criteria in solid tumours: revised RECIST guideline (version 1.1). European journal of cancer. 2009; 45(2):228-247.

27. Wang R, Chadalavada K, Wilshire J, Kowalik U, Hovinga KE, Geber A, Fligelman B, Leversha M, Brennan C and Tabar V. Glioblastoma stem-like cells give rise to tumour endothelium. Nature. 2010; 468(7325):829-833.

28. Deng Y, Su Q, Mo J, Fu X, Zhang Y and Lin EH. Celecoxib downregulates CD133 expression through inhibition of the Wnt signaling pathway in colon cancer cells. Cancer Invest. 2013; 31(2):97-102.

29. North TE, Babu IR, Vedder LM, Lord AM, Wishnok JS, Tannenbaum SR, Zon LI and Goessling W. PGE2-regulated wnt signaling and $\mathrm{N}$-acetylcysteine are synergistically hepatoprotective in zebrafish acetaminophen injury. Proceedings of the National Academy of Sciences of the United States of America. 2010; 107(40):17315-17320.

30. Takahashi-Yanaga F and Kahn M. Targeting Wnt signaling: can we safely eradicate cancer stem cells? Clinical cancer research : an official journal of the American Association for Cancer Research. 2010; 16(12):3153-3162.

31. Li HJ, Reinhardt F, Herschman HR and Weinberg RA. Cancer-stimulated mesenchymal stem cells create a carcinoma stem cell niche via prostaglandin E2 signaling. Cancer Discov. 2012; 2(9):840-855.

32. Al-Kharusi MR, Smartt HJ, Greenhough A, Collard TJ, Emery ED, Williams AC and Paraskeva C. LGR5 promotes survival in human colorectal adenoma cells and is upregulated by PGE2: implications for targeting adenoma stem cells with NSAIDs. Carcinogenesis. 2013; 34(5):11501157.

33. Rudnick JA, Arendt LM, Klebba I, Hinds JW, Iyer V, Gupta PB, Naber SP and Kuperwasser C. Functional heterogeneity of breast fibroblasts is defined by a prostaglandin secretory phenotype that promotes expansion of cancer-stem like cells. PloS one. 2011; 6(9):e24605.

34. Zhang Y, Wang J, Wheat J, Chen X, Jin S, Sadrzadeh H, Fathi AT, Peterson RT, Kung AL, Sweetser DA and Yeh JR. AML1-ETO mediates hematopoietic self-renewal and leukemogenesis through a COX/beta-catenin signaling pathway. Blood. 2013.

35. Moon CM, Kwon JH, Kim JS, Oh SH, Jin Lee K, Park JJ, Pil Hong S, Cheon JH, Kim TI and Kim WH. Nonsteroidal anti-inflammatory drugs suppress cancer stem cells via 
inhibiting PTGS2 (cyclooxygenase 2) and NOTCH/HES1 and activating PPARG in colorectal cancer. International journal of cancer Journal international du cancer. 2013.

36. Patel L, Pass I, Coxon P, Downes CP, Smith SA and Macphee $\mathrm{CH}$. Tumor suppressor and anti-inflammatory actions of PPARgamma agonists are mediated via upregulation of PTEN. Curr Biol. 2001; 11(10):764-768.

37. Rountree CB, Ding W, He L and Stiles B. Expansion of CD133-expressing liver cancer stem cells in liver-specific phosphatase and tensin homolog deleted on chromosome 10-deleted mice. Stem Cells. 2009; 27(2):290-299.

38. Lee SY, Lee GR, Woo DH, Park NH, Cha HJ, Moon YH and Han IS. Depletion of Aurora A leads to upregulation of FoxO1 to induce cell cycle arrest in hepatocellular carcinoma cells. Cell cycle. 2013; 12(1):67-75.

39. Wang C, Cigliano A, Delogu S, Armbruster J, Dombrowski F, Evert M, Chen X and Calvisi DF. Functional crosstalk between AKT/mTOR and Ras/MAPK pathways in hepatocarcinogenesis: implications for the treatment of human liver cancer. Cell cycle. 2013; 12(13):1999-2010.

40. Dubrovska A, Kim S, Salamone RJ, Walker JR, Maira SM, Garcia-Echeverria C, Schultz PG and Reddy VA. The role of PTEN/Akt/PI3K signaling in the maintenance and viability of prostate cancer stem-like cell populations. Proceedings of the National Academy of Sciences of the United States of America. 2009; 106(1):268-273.

41. Matsubara S, Ding Q, Miyazaki Y, Kuwahata T, Tsukasa K and Takao S. mTOR plays critical roles in pancreatic cancer stem cells through specific and stemness-related functions. Scientific reports. 2013; 3:3230.

42. Muramatsu S, Tanaka S, Mogushi K, Adikrisna R, Aihara A, Ban D, Ochiai T, Irie T, Kudo A, Nakamura N, Nakayama K, Tanaka H, Yamaoka S and Arii S. Visualization of stem cell features in human hepatocellular carcinoma reveals in vivo significance of tumor-host interaction and clinical course. Hepatology. 2013; 58(1):218-228.

43. Mitchem JB, Brennan DJ, Knolhoff BL, Belt BA, Zhu Y, Sanford DE, Belaygorod L, Carpenter D, Collins L, Piwnica-Worms D, Hewitt S, Udupi GM, Gallagher WM, Wegner C, West BL, Wang-Gillam A, et al. Targeting tumor-infiltrating macrophages decreases tumor-initiating cells, relieves immunosuppression, and improves chemotherapeutic responses. Cancer research. 2013; 73(3):1128-1141.

44. Wei J, Wang F, Kong LY, Xu S, Doucette T, Ferguson SD, Yang Y, McEnery K, Jethwa K, Gjyshi O, Qiao W, Levine NB, Lang FF, Rao G, Fuller GN, Calin GA, et al. miR124 Inhibits STAT3 Signaling to Enhance T Cell-Mediated Immune Clearance of Glioma. Cancer research. 2013; 73(13):3913-3926.

45. Ponthan F, Wickstrom M, Gleissman H, Fuskevag OM, Segerstrom L, Sveinbjornsson B, Redfern CP, Eksborg S, Kogner P and Johnsen JI. Celecoxib prevents neuroblastoma tumor development and potentiates the effect of chemotherapeutic drugs in vitro and in vivo.
Clinical cancer research : an official journal of the American Association for Cancer Research. 2007; 13(3):1036-1044.

46. Lonnroth C, Andersson M, Nordgren S and Lundholm K. Downregulation of Prominin 1/CD133 expression in colorectal cancer by NSAIDs following short-term preoperative treatment. Int J Oncol. 2012; 41(1):15-23.

47. Maddrey WC, Maurath CJ, Verburg KM and Geis GS. The hepatic safety and tolerability of the novel cyclooxygenase-2 inhibitor celecoxib. Am J Ther. 2000; 7(3):153-158.

48. Simioni C, Martelli AM, Cani A, Cetin-Atalay R, McCubrey JA, Capitani S and Neri LM. The AKT inhibitor MK-2206 is cytotoxic in hepatocarcinoma cells displaying hyperphosphorylated AKT-1 and synergizes with conventional chemotherapy. Oncotarget. 2013; 4(9):14961506.

49. Paik YH, Kim JK, Lee JI, Kang SH, Kim DY, An SH, Lee SJ, Lee DK, Han KH, Chon CY, Lee SI, Lee KS and Brenner DA. Celecoxib induces hepatic stellate cell apoptosis through inhibition of Akt activation and suppresses hepatic fibrosis in rats. Gut. 2009; 58(11):15171527.

50. Gao JH, Wen SL, Yang WJ, Lu YY, Tong H, Huang ZY, Liu ZX and Tang CW. Celecoxib Ameliorates Portal Hypertension of the Cirrhotic Rats through the Dual Inhibitory Effects on the Intrahepatic Fibrosis and Angiogenesis. PloS one. 2013; 8(7):e69309.

51. Kuo HM, Lin CY, Lam HC, Lin PR, Chan HH, Tseng JC, Sun CK, Hsu TF, Wu CC, Yang CY, Hsu CM and Tai MH. PTEN overexpression attenuates angiogenic processes of endothelial cells by blockade of endothelin-1/endothelin B receptor signaling. Atherosclerosis. 2012; 221(2):341-349. 